\title{
R\&D, Innovative Collaborations and the Role of Public Policies
}

\author{
Riccardo Crescenzi
}

\section{Contents}

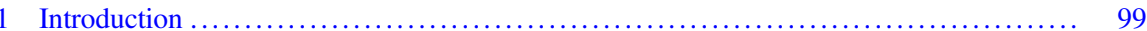

2 Balancing the Regional and the Global .................................... 100

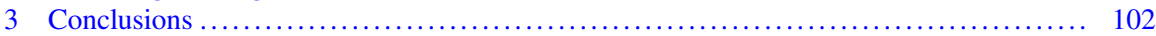

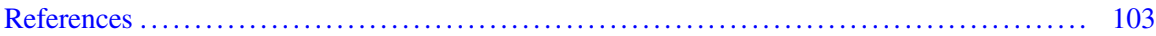

\section{Introduction}

The generation and diffusion of new knowledge and innovation in national, regional and local economies depends on efforts and investments in Research and Development (R\&D). These investments need to be coupled by the presence of appropriate Human Capital and skills in the public and the private sectors in order to absorb and diffuse innovation through the entire economy. Figure 1 summarises the results of recent research on the fundamental drivers of local innovation in Europe [1]. The surface 3D plot shows how innovative output (Z-axis-measured by regional patents) responds to simultaneous changes in $\mathrm{R} \& \mathrm{D}$ (Y-axis-measured by local expenditure in R\&D) and Human Capital (X-axis - measured by the presence in the same local economy of individuals with university degrees). For low levels of Human Capital, the patent-R\&D relationship is flat, whereas for higher levels of Human Capital intensity, the influence of $R \& D$ investments on innovation is positive and increases sharply with a higher level of Human Capital.

Some of the research featured in this chapter has received funding from the European Research Council under the European Union's Horizon 2020 Programme H2020/2014-2020 (Grant Agreement n 639,633-MASSIVE-ERC-2014-STG). All errors and omissions are my own.

\footnotetext{
R. Crescenzi $(\bowtie)$

Department of Geography \& Environment, London School of Economics, London, UK

e-mail: R.Crescenzi@1se.ac.uk; http://personal.1se.ac.uk/crescenz
} 
Fig. 1 The joint effect of R\&D and Human Capital (HK) on regional patent intensity $\mathrm{K}, \mathrm{f}(\mathrm{RDr}, \mathrm{t}, \mathrm{HKr}, \mathrm{t})$. A 3D surface plot. Source: Charlot, S. Crescenzi R. and Musolesi A (2015) Journal of Economic Geography, Volume 15, Issue 6 , November 2015, Pages 1227-1259, https://doi.org/ 10.1093/jeg/lbu035. Article distributed under the terms of the Creative Commons Attribution License (http:// creativecommons.org/ licenses/by/4.0/)

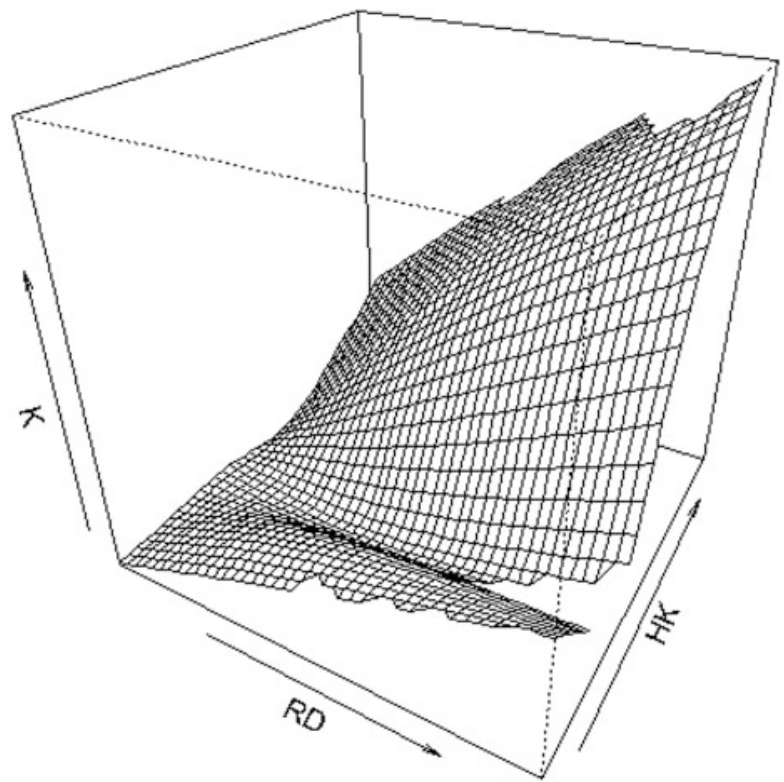

These findings suggest that $\mathbf{R} \& \mathbf{D}$ investments and facilities do have the potential to boost innovation at the local level. However, this only happens where appropriate complementary skills and conditions are available locally to support knowledge generation and absorption. Investments in R\&D can enhance regional innovation only when coupled with a supportive endowment of Human Capital. Both are needed simultaneously to boost innovation, and investing in R\&D does not appear to produce a positive effect on innovation for low levels of Human Capital.

\section{Balancing the Regional and the Global}

In this context, the richer regions of the European Union (EU) benefit from a persistent advantage in terms of the innovation returns to R\&D efforts. Conversely, economically disadvantaged regions appear to be in an innovation trap in the sense that a marginal increase in R\&D or Human Capital would not increase their ability to innovate. For these regions, investing marginally in such inputs would be wasting money. In particular, the return to R\&D expenditure is maximized between 2 and $3 \%$ of regional GDP, whereas Human Capital has a positive effect when at least $20 \%$ of the regional population has completed tertiary education. The analysis of innovation in EU regions [1] also highlights the presence of shadow effects: high levels of external $R \& D$ in neighbouring regions are detrimental for regions with low levels of internal $R \& D$, and the highest joint impact of internal and external $R \& D$ is obtained in the correspondence of the highest level of both inputs. 
Overall this evidence highlights the risk of 'cathedrals in the desert' scenario, where major R\&D investments are concentrated (e.g. because of policy decisions on the location of research infrastructure or localised incentives for private research programmes) in regions that lack the appropriate receptive environment in terms of Human Capital and other systemic conditions. The local mismatch between R\&D and skilled labor can persistently hinder innovation and local spillovers.

How can this be avoided? How can public policies facilitate the embeddedness of R\&D investments and research infrastructure into local innovation systems? The key tool is collaboration.

The romantic notion that a new Nikola Tesla will emerge from the lab with the next AC motor (or an X-ray) increasingly belongs to a bygone era. While in the late 1970s around 75\% of EPO patent applications in the United Kingdom (UK) were filed by individual inventors, nowadays that figure is below $15 \%$. More than $80 \%$ of all patents are registered to more than one inventor, suggesting that collaboration in research and innovation has become the norm. Teams within the firm or the research centre, but also increasingly complex networks of researchers involving different firms, often in collaboration with universities, public agencies, and research centres drive the world of invention in the early twenty-first century. As Seaborn [2] puts it, "big science [has] eclipsed the garage inventor [...] Edison has been superseded by a team of white-coated theoretical physicists".

This fundamental trend towards collaboration in patenting activity is documented in Fig. 2 that plots the share of co-invented patents (i.e. patents filed by two inventors or more) in the United Kingdom since 1978.

While the trend towards the formation of ever-larger research teams and inventor networks has been well documented, we know much less about the factors that drive researchers to collaborate with one another in the first place. How important is geographical proximity and spatial clustering for successful collaborations to happen? What can be done to facilitate local collaborations and spillovers?

Crescenzi et al. [3] have studied empirically the behaviour of 'multiple patent' inventors-i.e. the most prolific and innovative individuals in the economy-showing that being part of the same organisation plays a key role in the formation of co-patenting teams. However, social networks and cognitive proximities are key factors in shaping the selection of team members with a limited direct role of geographical proximity. The role of geographical proximity only emerges as well in interaction with other factors reinforcing their role. This suggests that local collaborations between large research centres and their local environment have the potential to happen but other conditions - to be carefully examined and assessedneed to be in place.

Similar conclusions are reached in [4] looking at the University-Industry collaborations (U-I) collaborations. By looking at the collaborative behaviour of all Italian inventors over the 1978-2007 period, the empirical analysis shows that U-I collaborations are less likely to happen when compared to collaborations involving exclusively university partners of business partners, and suggests that they tend to generate patents of more general applicability in subsequent inventions-measured 


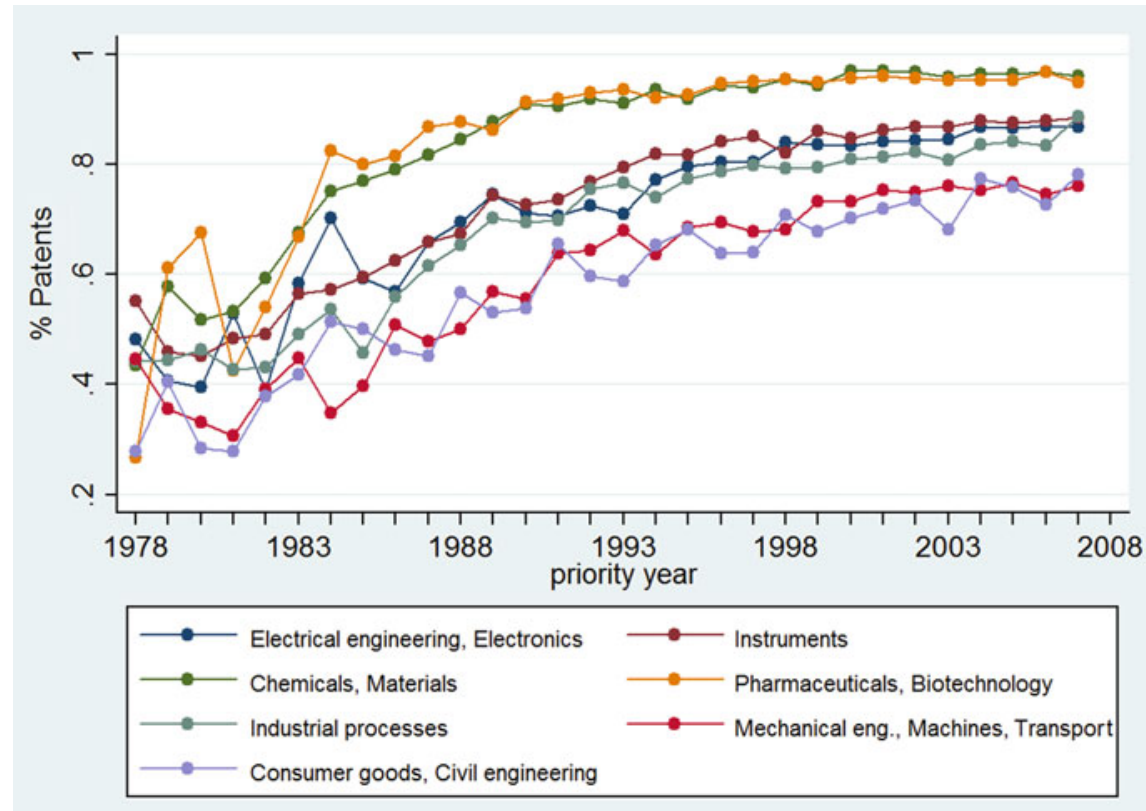

Fig. 2 Co-invented patents by technology field in the United Kingdom, 1978-2007. Source: Crescenzi R., Nathan M., Rodríguez-Pose A. "Do Inventors Talk to Strangers? On Proximity and Collaborative Knowledge Creation”, Research Policy, 45(1), 177-194, 2016, doi: https://doi.org/ 10.1016/j.respol.2015.07.003. This is an open access article under the CC BY license (http:// creativecommons.org/licenses/by/4.0/)

by forward-citations. As emphasized by the literature, geographical proximity plays an important role in facilitating all forms of collaboration. At the same time, it works as a possible substitute for institutional proximity, facilitating U-I collaborations. However, the involvement of 'star inventors' on both sides of the collaboration can play an equally important role in 'bridging' universities and industry.

\section{Conclusions}

Policy-makers have been attracted for a long time by the concept of innovation clusters with the objective of boosting overall regional innovation, development and employment. Public research centres and large research facilities have often been a core part of these local innovation strategies and have allocated substantial public resources to their support and promotion. The rationale behind these policies has been provided by the assumption that geographical clustering would per se support knowledge exchange and innovation. Further analysis on the complementarities between geographical proximity and other forms of proximities is crucial in this 
regard. An emerging body of evidence seems to increasingly point in the direction of an ancillary role being played by spatial clustering: if other proximity conditions are not simultaneously in place, spatial clustering may-as recent research seems to point out — be of limited utility to innovation. Conversely, public policies might have an important role to play acting as bridges in order to facilitate the development of connections between local teams and those active in the research facility. The presence of star researchers in large research facilities might - for example-be a key factor to facilitate collaboration with local industrial partners offering significant opportunities for technological upgrading.

\section{References}

1. Charlot S., Crescenzi R. \& Musolesi A. "Econometric Modelling of the Regional Knowledge Production Function in Europe", Journal of Economic Geography,15(6), 1227-1259, 2015, doi: https://doi.org/10.1093/jeg/lbu035

2. Seaborn, T., 1979. Talking about the automat. The open channel. Softw. Pat. Inst.(IEEE Comput.) $12,87-88$

3. Crescenzi R., Nathan M., Rodríguez-Pose A. "Do Inventors Talk to Strangers? On Proximity and Collaborative Knowledge Creation”, Research Policy, 45 (1), 177-194, 2016, doi: https://doi. org/10.1016/j.respol.2015.07.003 [Open Access]

4. Crescenzi R., Filippetti A., Iammorino S., "Academic Inventors: Collaboration and Proximity with Industry", Journal of Technology Transfer, 42(4), 730-762, 2017, doi: https://doi.org/10. 1007/s10961-016-9550-z [Open Access]

\section{Full Presentation}

https://indico.cern.ch/event/727555/contributions/3461299/attachments/1868119/3072744/ Crescenzi_FCC_CERN_June_2019.pdf

Open Access This chapter is licensed under the terms of the Creative Commons Attribution 4.0 International License (http://creativecommons.org/licenses/by/4.0/), which permits use, sharing, adaptation, distribution and reproduction in any medium or format, as long as you give appropriate credit to the original author(s) and the source, provide a link to the Creative Commons licence and indicate if changes were made.

The images or other third party material in this chapter are included in the chapter's Creative Commons licence, unless indicated otherwise in a credit line to the material. If material is not included in the chapter's Creative Commons licence and your intended use is not permitted by statutory regulation or exceeds the permitted use, you will need to obtain permission directly from the copyright holder.

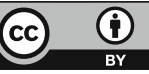

